\title{
Automatic control design and thermal performance of a solar fresh air system coupled with Latent Heat Thermal Storage tank
}

\author{
Wangli $\mathrm{Li}^{1, \mathrm{a}}$, Dingnai Xiu ${ }^{1, \mathrm{~b}}$, Wangmei $\mathrm{Jia}^{2, \mathrm{c}}$ \\ ${ }^{1}$ College of Automation Electronic Engineering, Qingdao University of Science and Technology, \\ Qingdao, 266042, China \\ 2 Qingdao Publishing \& Media Co., Ltd., Qingdao 266061, China

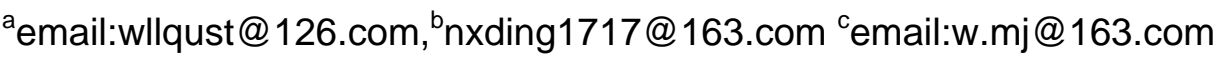

Keywords: Solar Fresh Air; LHTS; Field and remote control Design; iCAN module

\begin{abstract}
Concerning with the energy crisis, solar energy is considered to be one of the most promising alternative due to its zero gas emission. In this paper, a solar fresh air heating system coupled with Latent Heat Thermal Storage (LHTS) tank was designed. The solar energy is employed as heat supply source while the LHTS tank is used as heat storage device preventing from the instability and discontinuity of individual solar energy. The field and remote monitor and control of the fresh air system were finally implemented based on iCAN module. Experiments on the control system show that the design scheme is reasonable, on which we can make further research to obtain intelligent control of the fresh air.
\end{abstract}

\section{Introduction}

At present, residential space heating and domestic hot water primarily use the coal as the energy source in cold weather and thus causes energy consumption and serious environmental pollution. Therefore, there is an increasing interest in solar energy systems as an alternative energy source in current technologies as it represents a green and cheap source of energy. In addition, people desire a more comfortable living and working environment as the standard of living rises. In this situation, the solar fresh air system becomes one of the most promising applications that have been proposed which simultaneously solve the energy crisis and poor in-house air quality.

To improve the efficiency of the solar energy, the solar collectors should be placed with optimum angle of incidence which aims at concentrating a high percentage of the solar irradiances. However it still varies with the solar daily cycle and the passing clouds which will be the first challenge to deal with in order to provide stable and comfortable fresh air. In this paper, the LHTS device is employed primarily for storing the heat from the collectors which can be used to heat the fresh air when the solar is not sufficient for the fresh air. Research shows that as long as the water temperature of the solar collectors is higher than the phase transition temperature of phase change thermal storage device, the solar energy can be pre stored in heat storage device [1]. For the unique energy storage function of phase change material, the solar can be turned into stable heat source.

Thus, the paper is organized as follows: A description of the solar fresh air system is described in the following section. And the system performance issues are detailed in Section 3. In Section4 the control system including software and hardware structure is designed for field and remote monitoring control with the help of ICAN Module and TCP/IP technology. Finally, conclusions are commented in Section5.

\section{Solar Fresh Air System Description}

The solar fresh air system discussed in this paper is shown in Fig.1. It can operate in different modes which are controlled by changing the state of the pump and the valves. Solar collectors gather heat from sunlight into the water pipeline. The heated water will be stored in the LHTS device or make heat transfer with the fresh air through the heat exchanger. Thus it has functions of fresh air heating and heat storage which can work as a type of indoor auxiliary heating. 


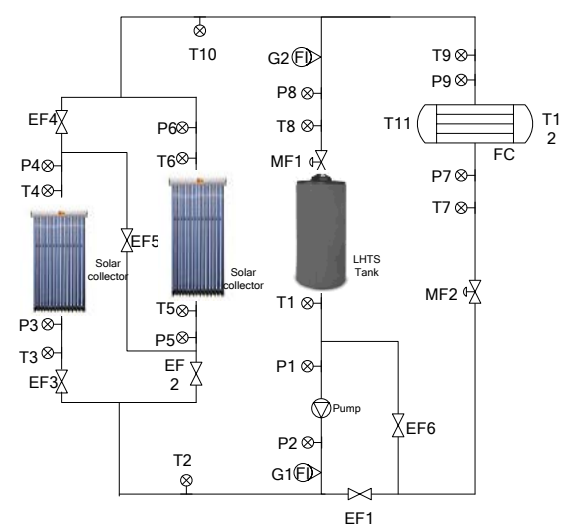

Fig.1. the fresh air system coupled with LHTS tank

Solar fresh air system consists of two parts, one is heat collecting part using the collectors to absorb the solar irradiation to heat the water, one solar collector or two collectors simultaneously are chosen to work according to the weather. And the other is heat storage part which is responsible for fresh air heating and remaining heat storage.

The collectors can receive the maximum solar radiation $\left(2191 \mathrm{MJ} / \mathrm{m}^{2}\right)$ when the angle is $64^{\circ}$ during winter heating period (11.15 3.15). The study found that using phase change material whose transition temperature is $42^{\circ} \mathrm{C}$ to $44^{\circ} \mathrm{C}$ is completely feasible to make hot water from the solar collector stable heat source[2]. The solar irradiance can reach $500 \mathrm{~W} / \mathrm{m}^{2}$ in winter, so the fresh air can be heated up to $27^{\circ} \mathrm{C}$ which indicates that not only does it not need to consume the system load, it can even afford part of indoor heating load[3].It is very suitable for heat storage of solar energy system.

The solar fresh air system can operate in three modes: (1) the necessary process heat for the fresh air is fully derived from solar irradiation. (2) All the solar irradiation is stored in the LHTS device. (3) A combined mode in which the process heat is derived from the combination of solar irradiation and the LHTS device during the period of low direct-normal solar irradiation.

\section{System Performance Analysis}

As we mentioned above, the solar fresh air system can operate in three modes. For each mode has its own characteristics, the mathematical model of the solar fresh air system varies with the different operating mode. The actuators of the system such as valves are nonlinear, and the parameters will change with time, device aging and replacement. Moreover, under different environmental conditions, the mathematical model is time-varying and uncertain in the fresh air system. For all the reasons discussed above, the mathematical model of the system is very difficult to establish [4].

Therefore, this study attempts to realize its model-free intelligent control which is mainly based on the experiment data and expert experience. In order to observe the different mode operating rules, the main device performances, at the same time to obtain the input and output data of the system, proper experimental design should be firstly finished in this paper.

\section{Experiment results}

Three modes are manually operated respectively to obtain characteristics of all parts of the system to prepare for realizing the intelligent control.

(1) Relationship between valve opening degree and flow rate by adjusting the valve.

From Fig2 we can see that in mode1 and mode2, the flow rate does not display until the valve opening degree is 0.15 from high to low adjustment, but the displaying degree is 0.21 when valve adjustment is from low to high, in which MF1 is the control valve of storage device circuit, and MF2 is control valve of fan coil loop. In mode3, the relation between valve opening and flow rate is shown in fig3 in which G1 is the total flow, and G2 represents flow of the storage device. We can see that the control valve has obvious characteristics of nonlinearity and drift. 


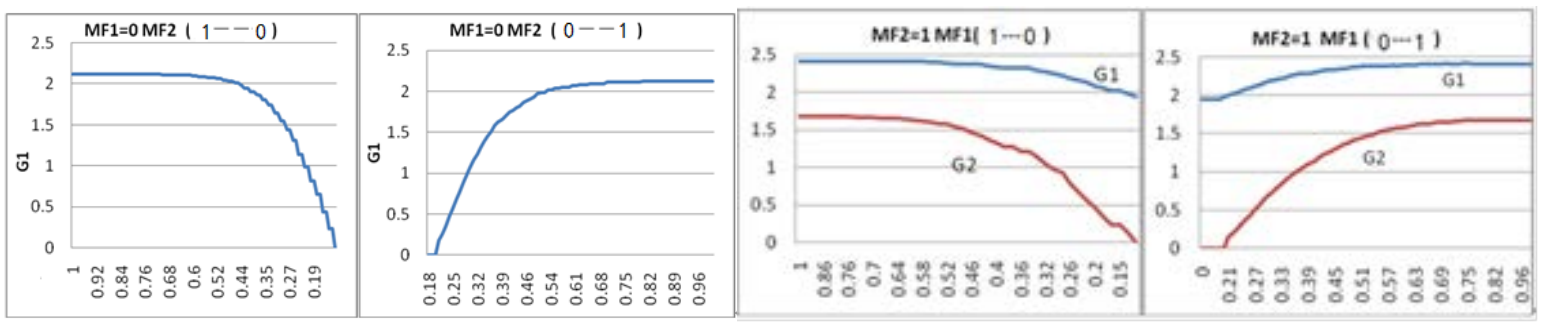

Fig2. Variation of G1 (mode1 mode2)

Fig3. Variation of G1 and G2 (mode3)

(2) Relationship between voltage and flow rate through regulation of inverter

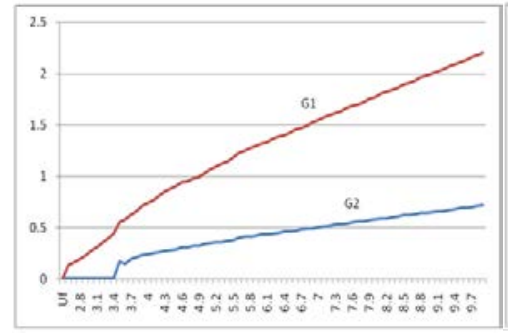

(a)MF1=0.3 MF2=1

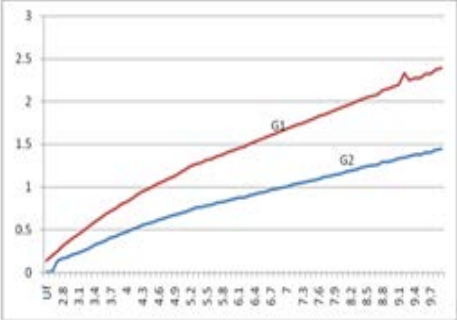

(b)MF1 $=0.5$ MF2 $=1$

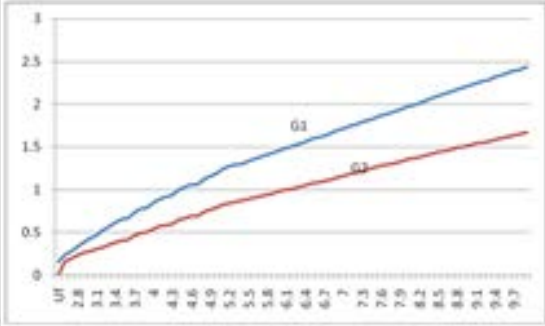

(c) MF1 $=0.7 \mathrm{MF} 2=1$

Fig. 4 flow rate curve

In mode 1 and mode 2, the fresh air is controlled through frequency converter to adjust pump thus regulating the heated water flow rate. However, in mode3, the fresh air temperature will reduce precipitously when the heat storage device starts to work, which will deteriorate the system stability. Therefore, in this paper we use the valve for coarse adjustment and inverter for fine adjustment. The valve opening is located in three positions, and the relationship between voltage and flow rate is depicted in Figure 4 in which $U_{\mathrm{f}}$ is the voltage of frequency converter.

\section{Hardware Structure Design of Solar Fresh Air Control System}

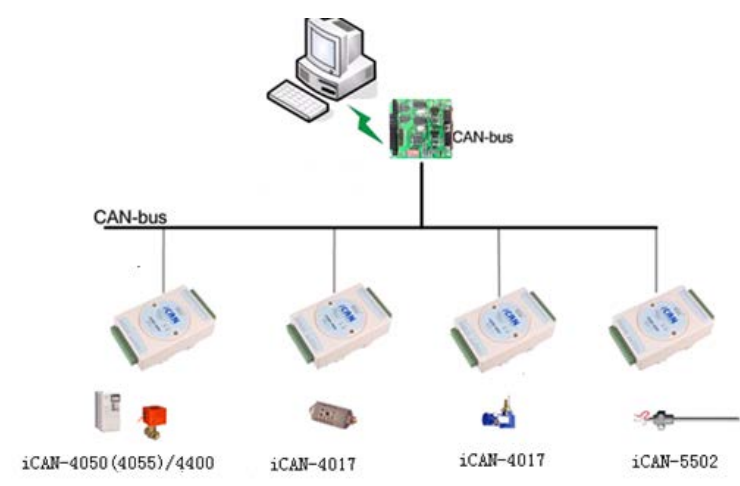

Fig. 5 Measurement and control system design with iCAN module

In the solar fresh air system, there are two kinds of valve, one is on-off valve which is used for mode chosen, and the other is control valve which is responsible for regulating the flow rate. There are three kinds of sensor, which is temperature sensor, pressure sensor and the flow sensor respectively.

The measurement and control system with iCAN module is depicted in Fig.5. The position machine is connected to CAN bus through intelligent interface card (USBCAN-2A/ II), the measurement and control of fresh air system are realized with iCAN module, of which the devices such as sensors and actuators are connected to iCAN modules through CAN bus. The field-data can be transmitted to the Position Machine, while the control order can be sent to iCAN module by the Position Machine [5]. 


\section{Software structure design of fresh air system}

The software structure design of fresh air system is based on C/S mode using LabWindows/CVI according to field and remote monitoring requirements.

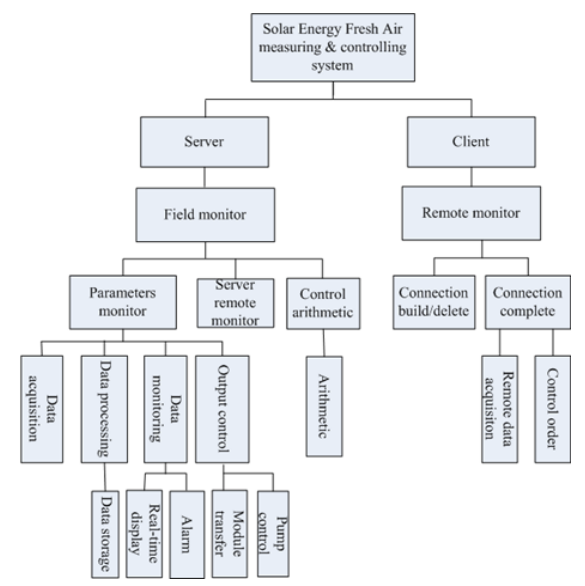

Fig.6 Software structure of the measuring and controlling system

The solar fresh air measuring and controlling system consist of field and remote monitoring, of which the field monitoring is responsible for parameters monitoring, server remote monitoring and control arithmetic while the remote monitoring is in charge of the registration and log-out of the server, also the data interactive with the client server when successful connection completed. The automatic control arithmetic will be discussed in another paper for the limited space.

\section{Conclusion}

A solar fresh air system coupled with LHTS was shown in this paper, and the thermal performance was discussed in detail for further intelligent control. Then the field and remote control of the system based on CAN bus is finally realized. It is proved that it is with high reliability, easy system operation, convenient monitoring interface for users, flexible network structure based on iCAN protocol, which lays a good foundation for further study of the control algorithm.

\section{Acknowledgement}

In this paper, the research was sponsored by Startup Foundation for Doctors of Qingdao University of Science and Technology.

\section{References}

[1] Shang Jianlei, Experimental investigation of solar energy based on latent heat thermal storage tank in winter heating fresh air system [D].Beijing: Beijing University of Technology, 2008

[2] LI Zhiyong, Theoretical and experimental study on solar heating system with phase change thermal storage [D].Beijing: Beijing University of Technology, 2011

[3] Weber, R; Dorer, V. Long-term heat storage with NaOH. Vacuum, v 82, n 7-14 March 2008, 708-716

[4] Wang lili, Control system study on solar heating system with phase change thermal storage [D].Beijing: Beijing university of posts and communications, 2010.

[5] Zhou,ligong .Application and Practice of iCAN Field Bus. [M].Beijing: Guangzhou Zhiyuan Electronics CO., LTD, 2007. 